\title{
GRUPOS DE EDUCAÇÃO EM SAÚDE: APRENDIZAGEM PERMANENTE COM PESSOAS SOROPOSITIVAS PARA O HIV
}

\author{
HEALTH EDUCATION GROUPS: LIFELONG LEARNING WITH HIV POSITIVE PEOPLE
}

\author{
Audrey Vidal Pereira ${ }^{1}$ \\ Ana Luiza Stiebler Vieira ${ }^{2}$ \\ Antenor Amâncio Filho ${ }^{3}$
}

Resumo Atualmente a epidemia de HIV/Aids está disseminada em todo o país e no mundo, infectando milhares de pessoas nos diferentes ciclos da vida. Deste modo, estratégias de prevenção, tanto individuais quanto coletivas, permanecem imprescindíveis para reduzir e controlar as taxas de transmissão. O objetivo do artigo é analisar as percepções dos profissionais de saúde sobre as práticas de educação em saúde realizadas por meio de ações coletivas com pessoas soropositivas para o HIV. Este estudo qualitativo de abordagem descritiva foi desenvolvido com profissionais de saúde em cinco instituições do município de Niterói, Rio de Janeiro. Foram utilizados a técnica de entrevistas semiestruturadas e o método de análise de conteúdo. A educação em saúde é vista pelos profissionais como modos de ensino e aprendizado, repasse de informações, troca de ideias e experiências, bem como crescimento mútuo, processo reflexivo e participativo, que contribui para minimizar sofrimentos, trabalhar expectativas e emoções, além de promover cidadania e qualidade de vida. As ações de educação em saúde possibilitariam recriar momentos participativos, interativos, cooperativos e inclusivos; suscitar desdobramentos socioafetivos e compromissos sociopolíticos; aproximar e humanizar as relações interpessoais; garantir acesso às medidas de prevenção, bem como auxiliar a produção de cuidados integrais capazes de promover saúde.

Palavras-chave HIV/Aids; educação em saúde; ações coletivas; profissionais de saúde.
Abstract The HIV/AIDS epidemic is widespread throughout the country and the world, having infected thousands of people in different life cycles. Thus, prevention strategies, both individual and collective, remain essential to reduce and control transmission rates. The purpose of this article is to analyze the health professionals' perceptions about health education practices carried out via collective actions among HIV-positive people. This qualitative study, which uses a descriptive approach, was developed alongside health professionals from five institutions in the city of Niterói, Rio de Janeiro. We used the semistructured interview technique and the content analysis method. The professionals view health education not only as a way to teach and learn, transfer information, exchange ideas and experiences, but also as a tool mutual growth, a reflective and participatory process that helps minimize suffering, to work on expectations and emotions, and to foster citizenship and quality of life. Health education actions enable the recreation of participatory, interactive, cooperative, and inclusive moments; they lead to social and affective development and to socio-political commitments; they draw people closer and humanize interpersonal relationships; they ensure access to prevention, and help produce comprehensive care that can promote health.

Keywords HIV/AIDS, health education, collective actions; health professionals. 


\section{Introdução}

Apesar dos avanços tecnológicos existentes no mundo contemporâneo, a prevenção de doenças e a promoção da saúde permanecem como questões cruciais para a manutenção da vida. A educação e a saúde, quando articuladas, demonstram possibilidades para uma assistência integral às pessoas, principalmente se forem realizadas por meio de ações coletivas.

Atividades em grupo propiciam encontros entre pessoas que compartilham situações comuns no cotidiano da vida. Por exemplo, variáveis como sexo e idade podem influenciar na aproximação de pessoas, caracterizando grupos que direcionem trabalhos específicos com adolescentes, mulheres e idosos. Ainda no campo da saúde podem existir outros fatores que delimitem tendências para a formação de trabalhos em grupo. Períodos como gestação e puerpério possibilitam o encontro de pessoas que necessitem refletir sobre temas específicos, como modificações no organismo da mulher, amamentação, sexualidade e cuidados com os recém-nascidos. Agravos à saúde acometidos por diabetes, hipertensão, hanseníase ou HIV/AIDS também direcionam o desenvolvimento de grupos que estimulem discussão sobre problemas comuns, troca de experiências e incentivo ao aprendizado de questões sobre cuidados de si, auxiliando na convivência com a própria doença.

Além de possibilitar acesso à informação e troca de experiências que contribuem para prevenção de morbidades e promoção da saúde, os trabalhos em grupo também poderiam estimular espaços de humanização, inclusão social e participação cidadã.

No entanto, cabe indagar até que ponto os serviços de referência ao acompanhamento de pessoas soropositivas para o HIV, além de realizarem uma assistência de qualidade que garanta tratamento eficaz com antirretrovirais e controle da carga viral através de exames laboratoriais, fomentariam em proporções equitativas a operacionalização de atividades de cunho preventivo, também extremamente importantes para o controle da epidemia. É a partir de questionamentos como esses que se pretende problematizar algumas das relações existentes entre educação e saúde, no âmbito das atividades de grupos voltadas para as pessoas que vivem com HIV.

Assim, o objetivo deste artigo é analisar as percepções dos profissionais de saúde sobre as práticas de educação em saúde realizadas por meio de ações coletivas com pessoas soropositivas para o HIV.

\section{Educação em saúde: o diálogo que permanece}

A perspectiva de educação que se pretende enfatizar aqui está apoiada nas concepções teóricas de Paulo Freire. São preconizados estímulos para con- 
dutas ativas e participativas, valorizando encontros que primem pelo esforço em promover diálogos e troca de ideias e experiências, a fim de compartilhar momentos em que tanto educando quanto educador aprendam e ensinem reciprocamente.

Isso significa dizer que um processo educativo não deve ser compreendido como algo fechado em que o conhecimento pode ser depositado no outro, como se observa na crítica de Paulo Freire à 'educação bancária' . Mas, sim, que é um processo em que educando e educador, de modo bilateral, encontrem meios que promovam independência e capacidades de questionamentos, críticas e reflexões, possíveis de promover uma ação educativa autêntica que não se faz de ' $\mathrm{A}$ ' para ' $\mathrm{B}$ ' ou de 'A' sobre ' $\mathrm{B}$ ', mas de 'A' com ' $\mathrm{B}$ ' mediatizados pelo mundo (Freire, 1997).

Também no âmbito da saúde, entende-se que o objetivo da educação é o de oportunizar momentos de reflexões e ações capazes de possibilitar às pessoas um aprendizado consciente, sem a intenção de controlar suas vidas. A educação em saúde vista neste contexto pode ser compreendida no sentido de propiciar encontros entre profissional e usuário do serviço de saúde. Esta relação face a face representa uma maneira de fomentar o diálogo e a troca de experiências.

Stotz (2007) chama atenção quanto ao uso da preposição 'em' no conceito educação em saúde, fazendo referência ao desempenho que os serviços de saúde apresentam em termos de controle social dos doentes e das populações 'de risco'. Desta forma, os profissionais necessitam vivenciar educação em saúde de modo crítico e reflexivo, esforçando-se para não trabalharem com verdades absolutas, imutáveis ou demonstrações de modelos e comportamentos padrões.

A educação no âmbito da saúde deve ter como princípio estimular experiências que facilitem a realização de ações que melhorem as condições de vida e promovam saúde. Para tal, cabe ressaltar a importância de habilidades individuais e da participação coletiva, a fim de fortalecer processos autônomos dos sujeitos e dos grupos sociais, que, a partir do contexto socioeconômico, político e cultural, possibilitem mudanças nas práticas de saúde e melhorem a condição e qualidade de vida da população (Czeresnia e Freitas, 2003).

A esse respeito, Vasconcelos (2007) ressalta que a educação em saúde é um campo de práticas e conhecimentos que tem se ocupado com a criação de vínculos entre a ação profissional e o pensar e fazer cotidiano da população.

A educação em saúde deve estar comprometida com a prática de reflexões que desenvolvam a liberdade da pessoa, a fim de colocar em movimento seu modo de ser/estar perante o outro e o mundo que o rodeia. Educar em saúde é mais do que instruir. É acreditar na reflexão e no diálogo entre pessoas, oportunizando uma ação cultural que possibilite independência emocional (Freire, 1997). 
A priori, a educação em saúde é uma construção em movimento, tanto pessoal quanto coletiva, que se amplia quando se trata de promoção à saúde. Daí, a importância de se trabalhar as situações conforme a realidade das pessoas, valorizando aspectos de sua cultura, as relações de gênero e os diferentes níveis socioeconômicos e políticos. O trabalhador profissional da saúde desempenha um papel educativo, e este trabalho pode estar presente nas diversas práticas desenvolvidas, tornando-se mais visível nas atividades de prevenção e promoção da saúde (Morosini, Fonseca e Pereira, 2007).

Além da criatividade, troca de vivências, trabalho coletivo, participação, valorização da diversidade e do envolvimento e criação de vínculo, o trabalho educativo realizado na área da saúde contribui para a construção de uma sociedade democrática e solidária.

As ações de educação em saúde, que se concretizam no cotidiano dos encontros entre profissionais e usuários do serviço, podem ser vivenciadas de modo oposto ao autoritarismo, ao depósito de conteúdos e à transmissão vertical do conhecimento. Devem acontecer com ênfase no diálogo, crítica, ação e reflexão.

Segundo Freire (1997), o diálogo é uma exigência existencial. É o encontro em que se solidarizam o refletir e o agir de sujeitos endereçados ao mundo a ser transformado e humanizado. Não pode ser reduzido a um ato de depositar ideias de um no outro, mas sim a um ato de criação responsável para libertação dos homens.

No entanto, no atual modelo de assistência à saúde ainda se verifica a prática de situações tradicionais. O corporativismo profissional que permite a realização de ações isoladas e de gerência verticalizada e autoritária, estrutura uma organização de trabalho com visão restrita e individualizada, desencadeando práticas assistenciais que compartimentalizam o ser humano e dificultam posturas críticas e reflexivas.

Marcondes (2007) afirma que educadores e educandos se encontram sob uma mesma matriz autoritária que conserva as relações sociais baseadas no poder conferido aos que detêm conhecimento. O mesmo pode ocorrer na relação entre profissionais da saúde e atores das camadas populares,ao serem enquadrados em modelos de participação na saúde que utilizem tecnologias e métodos bancários de ensino.

Para construir possibilidades de mudanças com relação à atenção à saúde, é necessário valorizar tanto os aspectos biológicos quanto os emocionais, sociais, políticos, econômicos, culturais e espirituais. Devem ser asseguradas atividades concomitantes que atendam também as perspectivas de participação social e cidadã, de prevenção de doenças e promoção da saúde.

Pode-se observar que a política de Humanização do Ministério da Saúde (Brasil, 2004) traz um incentivo quanto aos mecanismos de escuta, diálogo, 
acolhimento por parte dos profissionais, bem como à autonomia e ao protagonismo dos usuários. Sinaliza, também, que estas ações devem intrinsecamente atrelar-se às práticas das equipes de saúde e à vida cotidiana dos usuários, fazendo parte da cultura organizacional das instituições, sistema de saúde e sociedade. Desta maneira, a política de Humanização, por meio dos eixos estratégicos de atenção à saúde e educação permanente, apresenta correlações diretas com a abordagem aqui referida sobre saúde e educação.

Vasconcelos (2007) afirma que a educação é um instrumento para a construção da atenção integral à saúde, na medida em que se dedica à ampliação das relações entre as diversas profissões, serviços, usuários, familiares e organizações sociais locais.

Assim, as práticas educativas em grupo devem ser vivenciadas em larga escala nos serviços de saúde a fim de corroborar uma cultura preventiva universalizada para o conjunto da sociedade (Ayres, 2002), possibilitando contribuições imprescindíveis para uma atenção à saúde integral e de qualidade.

\section{Aspectos metodológicos}

O presente estudo, do tipo qualitativo e de abordagem descritiva, foi realizado durante o segundo semestre de 2005, com profissionais de saúde que desenvolviam atividades coletivas de educação em saúde, em instituições do município de Niterói, no estado do Rio de Janeiro.

Inicialmente foram identificadas 12 unidades que se apresentavam como referência ao tratamento de HIV/Aids. Dentre as 12, foram escolhidas cinco para a pesquisa de campo, pois somente essas realizavam atividades de grupo, atendendo ao objetivo do estudo, que é analisar as práticas de educação em saúde realizadas por meio de ações coletivas com pessoas soropositivas para o HIV.

O Quadro 1 apresenta um demonstrativo por unidade dos serviços oferecidos e dos profissionais em atividades ambulatoriais ou de grupo, em Niterói, Rio de Janeiro. Identifica por instituição: os serviços ambulatoriais; os participantes e as atividades de grupo realizadas; e o tipo de participação dos profissionais nas respectivas atividades (efetiva, pontual ou não-participação). 


\section{Quadro 1}

Serviços de referência ao HIV/Aids e profissionais em atividades ambulatoriais e/ou de grupo

\begin{tabular}{|c|c|c|}
\hline Unidades & Serviços oferecidos & Profissionais \\
\hline \multirow[t]{7}{*}{ Segurança **** } & Ambulatório infanto-juvenil & 4 assistentes sociais* \\
\hline & Ambulatório de adulto & 1 arte-terapeuta* \\
\hline & Leito-dia adulto e infantil & 6 pediatras $* *, 2$ hebiatras ${ }^{* *}$ \\
\hline & Urgência e internação & 1 infectologista $* * *$ \\
\hline & Atividades de grupo com adultos, crianças, & 2 psicólogos* \\
\hline & adolescentes e familiares & 2 pedagogas* \\
\hline & & 1 técnico de enfermagem* \\
\hline \multirow[t]{7}{*}{ Sigilo **** } & Ambulatório de pré-natal & 2 assistentes sociais* \\
\hline & Ambulatório de parceiros & 2 clínicos ${ }^{* *}, 4$ obstetras $* * *$ \\
\hline & Núcleo de violência sexual & 4 mastologistas $* * *$ \\
\hline & Patologia cervical e mamária & 1 nutricionista* \\
\hline & Atividades de grupo com gestantes & 1 psicóloga* \\
\hline & & 5 patologistas cervicais $* * *$ \\
\hline & & 2 técnicos de enfermagem $* * *$ \\
\hline \multirow[t]{8}{*}{ Educação **** } & Ambulatório infanto-juvenil & 2 assistentes sociais* \\
\hline & Ambulatório de adulto & 1 auxiliar de consultório dentário* \\
\hline & Ambulatório de pré-natal & 1 cirurgiã-dentista* \\
\hline & Ambulatório de odontologia & 2 enfermeiras* \\
\hline & Núcleo de violência sexual & 3 clínicos** \\
\hline & Atividades de grupo com adultos, crianças e familiares & 1 infectologista ${ }^{* *}$ e residentes ${ }^{* * *}$ \\
\hline & & 2 nutricionistas* \\
\hline & & 1 psicóloga* \\
\hline \multirow[t]{4}{*}{ Prestígio **** } & Ambulatório de adulto & 2 assistentes sociais* \\
\hline & Centro de testagem anônima & 2 enfermeiras* \\
\hline & Atividades de grupo com adultos & 2 médicos infectologistas $* * *$ \\
\hline & & 2 psicólogos* \\
\hline \multirow[t]{6}{*}{ Esforço **** } & Ambulatório de adulto & 1 assistente social* \\
\hline & Atividades de grupo com adultos & 1 bióloga-chefe de vigilância em saúde* \\
\hline & & 2 clínicos*** \\
\hline & & 1 endocrinologista ${ }^{* * *}$ e 1 infectologista $* * *$ \\
\hline & & 1 enfermeiro** \\
\hline & & 1 psicóloga** \\
\hline
\end{tabular}

Fonte: Os autores.

Notas: * Participação 'efetiva' nas atividades de grupo; ** Participação 'pontual' nas atividades de grupo; *** 'Não participação' nas atividades de grupo; **** Pseudônimos caracterizam as correlações entre o perfil das ações realizadas em cada unidade e o objeto de estudo.

Uma vez identificadas as unidades, e mediante indicações da coordenadora de DST/Aids do município, foram feitos contatos com as direções 
das instituições a fim de expor os objetivos e a forma de realização da pesquisa, além da apresentação e recolhimento de assinatura do termo de autorização da instituição participante.

Os sujeitos do estudo que realizavam as atividades de grupo perfizeram um total de 35 profissionais, que foram divididos entre os que participavam de modo efetivo (assistente social, enfermeiro, psicólogo, cirurgião dentista, nutricionista e biólogo) e os que apresentavam inserção pontual (médicos e coordenação municipal do programa de DST/Aids), como pode ser visualizado no Quadro 1.

Após explicações sobre o desenvolvimento do estudo, os profissionais selecionados assinaram o Termo de Consentimento Livre e Esclarecido e aceitaram gravar os diálogos em fitas de áudio, cabendo ressaltar que não houve recusa de participação por parte de nenhum deles. Foram atendidos todos os passos preconizados pela resolução n. ${ }^{\circ}$ 196/1996, do Conselho Nacional de Saúde, sendo a pesquisa aprovada pelo Comitê de Ética em Pesquisa da Escola Nacional de Saúde Pública Sergio Arouca, da Fundação Oswaldo Cruz.

Para garantir o anonimato, os participantes foram identificados por pseudônimos, escolhidos por eles mesmos, em uma lista de palavras previamente elaborada (Ex.: afinidade, encontro, vínculo, atenção etc.), e disponibilizada no momento das entrevistas, que foram realizadas utilizando-se um roteiro semiestruturado. Esse roteiro apresentava questões sobre as dinâmicas aplicadas no processo de realização dos grupos; o perfil e ações dos profissionais envolvidos nas práticas de grupo; as facilidades e dificuldades para a prática de grupo; e o entendimento do conceito de educação em saúde por parte dos profissionais entrevistados. O instrumento foi utilizado como norteador da entrevista não tendo uma sequência exata a ser seguida.

Para análise das entrevistas e organização das falas, elegeu-se a análise de conteúdo por meio da modalidade temática - uma das formas que tem por intenção obter um substrato de representação que expresse de modo mais fiel possível o que pensa determinada população sobre dado tema. Com relação a esta técnica, Bardin (2009) esclarece que é uma contagem de um ou vários temas ou itens de significação, numa unidade de codificação (a frase) previamente determinada.

Buscou-se a coerência entre as falas. Foram agregados os trechos isolados (itens de significação) dos depoimentos, de modo a formar grandes categorias ou núcleos temáticos, nos quais o conteúdo sintetizado de modo coerente foi capaz de fazer com que cada uma das partes envolvidas se reconhecesse como constituinte do todo e este todo como constituído pelas partes (Bardin, 2009).

Essa etapa possibilitou a caracterização de três núcleos temáticos: 1) o conceito de educação em saúde construído a partir das falas profissionais; 2) experiências coletivas: modos de ensino-aprendizado e crescimento mútuo; 3) reflexão e participação: trabalhando emoções, cidadania e qualidade de vida. 


\section{Resultados e discussão}

Neste item, buscou-se analisar os resultados das falas dos profissionais de saúde referentes às práticas de grupos educativos e suas percepções quanto às suas vivências nas atividades coletivas de educação em saúde realizadas com pessoas que vivem com HIV.

\section{O conceito de educação em saúde a partir das falas profissionais}

Os profissionais entrevistados, num processo de elaboração do conceito de educação em saúde, sinalizaram que tanto educação quanto saúde são fundamentais para a vida, sendo mecanismos interdependentes que possibilitam realizar aproximações com as pessoas soropositivas para o HIV.

Educação em saúde eu acho que é acessar essa comunidade... eu acho que andam juntas... caminham de mãos dadas (Assistente social - afinidade).

(...) educação em saúde eu acho que é essencial na vida das pessoas (Psicóloga vínculo).

As falas manifestaram ideias de que o conceito está atrelado aos modos de ensinar, esclarecer, orientar e de passar informações, deixando transparecer correlações com ações que caracterizam prevenção de doenças.

Educação em saúde eu acho que é uma coisa que é ampla... Você tem que colocar toda informação, no caso aqui a gente coloca informação voltada pra prevenção. Educação em saúde é você dar a informação (Enfermeira - encontro).

Todavia, Morosini, Fonseca e Pereira (2007) alertam que a compreensão de educação como ato normativo e prescritivo ainda predomina, fazendo com que o sujeito seja reduzido a objeto passivo da intervenção educativa.

Entretanto, a prática educativa não deve ser resumida apenas em transmitir informações e correlacionada simplesmente ao repasse de orientações, mas também deve ser responsável por estimular a aprendizagem mútua, além de postura crítica, reflexiva e participativa, de modo que seja possível construir novos conhecimentos e práticas para a promoção da saúde (Marcondes, 2007).

Deste modo, também se identificaram falas em que os profissionais enfatizaram a concepção voltada para promoção de saúde, numa aproximação que se pode correlacionar às fundamentações teóricas de Freire (1996, 1997). 
Educação em saúde é muita coisa. É a possibilidade de escutar o outro, de crescer com o outro, de aprender com o outro, valorizar o outro também. De abrir espaço... E de estar trocando (Assistente social - interação/troca).

Educação em saúde? Ah!... Eu acho que não tenho nenhum conceito muito organizado na minha cabeça, mas eu entendo que são todas as práticas nossas de estar tentando não ensinar, porque eu acho que a gente não ensina nada pra ninguém. A gente aprende, troca, discute, contribui... (Cirurgiã dentista - atenção).

Freire (1997) afirma que a educação vivenciada por aqueles que verdadeiramente se comprometem com a libertação não pode efetivar-se numa compreensão dos homens como seres 'vazios' a quem o mundo 'encha' de conteúdos, mas deve ser consolidada a partir da problematização dos homens em suas relações com o mundo.

O processo de educação em saúde também pôde ser percebido como modo de incentivar a participação popular e o respeito à autonomia, a fim de que as pessoas vivenciassem ações de cidadania, troca cultural e diálogo, auxiliando, assim, na governabilidade da própria vida, na mediação da relação entre usuários e serviços de saúde e na redefinição da vida social na direção de uma saúde integral (Vasconcelos, 2004).

Então não são como práticas de boa higiene... é entrar em contato com essa pessoa de modo que ela possa gerir as suas questões... a própria pessoa gerar e consequentemente gerar o poder ou uma necessidade de reivindicação... (Psicólogo alteridade).

Em suma, surgiram concepções teóricas e posicionamentos que foram desde a percepção tradicional de educação em saúde, em que se focalizaram a transmissão de informações e o controle das pessoas, até a ideia de trocas de experiências, de incentivo da participação social e da autonomia para promoção da saúde.

\section{Experiências coletivas: modos de ensino-aprendizado e crescimento mútuo}

Com relação às atividades coletivas desenvolvidas pelos profissionais de saúde, surgiram falas apontando a existência de diferentes concepções de grupo: de adesão, revelação diagnóstica, apoio, convivência, 'educação', aconselhamento, terapia e reflexão. ${ }^{4}$ Estas concepções possibilitaram caracterizações de grupo que se aproximaram de diversas áreas do conhecimento, com destaque para sociologia, psicologia e educação. No caso deste estudo, 
independentemente da multiplicidade de conceitos, as práticas de grupo responsáveis por interação de pessoas que aceitavam acordos, regras e objetivos similares foram consideradas como espaços compartilhados de ensinoaprendizado que auxiliam na vida social.

Dias, Silveira e Witt (2009) ressaltam que um grupo pode ajudar as pessoas viabilizando suporte durante períodos de ajustamento a mudanças, no tratamento de crises ou ainda na manutenção ou adaptação a novas situações.

Numa visão processual, as práticas das concepções de grupo citadas acima podem caminhar paralelas ou sobrepostas, no entanto dependem da disponibilidade e das características individuais do profissional ou ainda da demanda que surge dos componentes do grupo. Dessa forma, o grupo poderá ter o perfil de quem o coordena, como observado nas falas a seguir.

Mas é óbvio que na hora do trabalho, essa característica individual, ela vai estar colocada. Meu olhar vai estar com olhar... uma ênfase um pouco mais em cima da minha formação. Por exemplo, quando o grupo é feito pelo psicólogo, ele pode ter mais esse olhar de apoio terapêutico" (Assistente social - pertencimento).

Assim, você [psicóloga] tem elementos de interpretação, elementos de elaboração bastante diferentes. (...) você organiza um grupo de apoio de uma forma bastante diferente de uma assistente social" (Psicóloga - vínculo).

Nessas atividades de grupo, os profissionais pontuaram que a participação individual precisa ser incentivada, devendo ser garantido espaço para escuta e diálogo. É necessário, pois, que exista respeito mútuo, para que os encontros sejam vivenciados por meio de relações próximas e de igual para igual (troca horizontal), e não como momentos de repasse verticalizado de informações. Deve haver um ambiente propício a desacelerar os ânimos, aliviar ansiedades, conflitos e tensões, melhorar a concentração, desenvolver o prazer de aprender e de estar com o outro. Um espaço capaz de desenvolver aprendizagem recíproca e educar os sentimentos e emoções. Segundo Goleman (2001), quando as emoções são contidas, geram embotamento e frieza; quando escapam ao controle, tornam-se patológicas, tal como ocorre na depressão paralisante, na ansiedade que destrói, na raiva alucinada e na agitação maníaca.

Ao realizar o grupo com uma perspectiva de tirar dúvidas, trocar experiências e ideias, promover debates e mediar conflitos, surge nas falas dos profissionais o reconhecimento da importância de uma relação face a face, que se opõe às ações prescritivas, expositivas, autoritárias e normativas de condutas e de comportamentos.

Cury (2003) salienta que a exposição dialogada objetiva desenvolver a consciência crítica, promover o debate e a educação participativa, melhorar 
a insegurança, a timidez e a concentração, além de abrir espaço para uma discussão positiva, disponibilizando, por meio de afinidades e empatias, um processo de escuta, diálogo e troca de experiências.

Como diz Freire (1997), os homens não se fazem no silêncio, mas na palavra, no trabalho e na ação-reflexão. É por meio do diálogo que o ser humano se descobre como sujeito, tornando o encontro educativo um momento de crescimento individual, em que deve ser o sujeito de sua própria história, e não o seu objeto.

Assim, entende-se que seja importante para os profissionais que realizam grupos assumir posturas de facilitadores ou condutores do processo de ensino-aprendizagem, inseridos numa dinâmica de convivência de responsabilidades compartilhadas e democráticas, como explicitado a seguir:

(...) pra que estas famílias se sentissem acolhidas, tivessem um espaço pra discutir, um espaço pra trocar ideias... aí surgiu a ideia de se fazer grupos com esses cuidadores (Assistente social - afinidade).

(...) há uma troca e eu acho que a gente cresce. E como profissional, estou crescendo muito. Eu acho que muito além da empatia, há uma troca... uma substituição também (Psicóloga - amizade).

Conforme mostra Merchán-Hamann (1999), faz-se necessário elaborar propostas de práticas de educação em saúde que incorporem, ao mesmo tempo, o reconhecimento da dignidade e integridade das pessoas envolvidas, bem como a construção de bases democráticas e igualitárias de comunicação, nas quais os educandos tanto quanto os educadores constituam sujeitos ativos em uma relação de reciprocidade e crescimento.

Os profissionais devem se comportar como facilitadores flexíveis no processo de troca de experiências, retirada de dúvidas e compartilhamento de conhecimento. Nesse sentido, eles sinalizaram que são inúmeras as oportunidades de crescimento e aprendizado:

(...) eu acho que o doente e a gente também se beneficia; que a gente acaba aprendendo um com o outro (Médico - liberdade).

(...) acho que isso é uma troca. Por mais que você seja treinado, você vê realidades, aí que você aprende muito. Além de aprender eu acho que você troca... (Enfermeira - encontro).

Freire (1997) afirma que o educador não é apenas o que educa, mas o que, ao educar e dialogar com o educando, igualmente é educado, e consequentemente ao ser educado, também educa. Isto significa que a experiência de 
vida, a sabedoria popular e a convivência em grupo possibilitam aprendizado tanto para o usuário quanto para o profissional.

\section{Reflexão e participação: trabalhando emoções, cidadania e qualidade de vida}

Vale destacar que o movimento de participação em grupo acaba gerando novas expectativas na vida profissional. Ao serem compartilhados, os processos reflexivos podem se tornar objetos sugestivos capazes de implementar ações futuras. Mesmo que necessitem de um prazo longo para serem operacionalizados, estes processos estão ligados à importância de um trabalho diário, gradativo e dinâmico.

Porque educação em saúde pressupõe discussão. Pressupõe continuidade pra que possa haver uma transformação... (...) você precisa de tempo... de tempo de relação naquele grupo... (...) então tem que ter paciência (Assistente social/Coordenação municipal DST/Aids - responsabilização).

A adoção da educação em saúde numa perspectiva de consolidar espaços democráticos faz com que as pessoas se envolvam num processo de aprendizagem recíproca, a fim de consolidar vínculos e alcançar resultados concretos. Para isso, é importante também reconhecer as histórias individuais, em que cada um, segundo Cury (2003), tem de ser autor de sua história para aprender a intervir em seu próprio mundo.

As pessoas soropositivas para o HIV apresentam histórias de vida peculiares, difíceis de exposição e compartilhamento, fazendo-se imprescindível procurar entender o tempo diferenciado que cada um leva para se envolver na dinâmica de grupo, cujo processo deve ser vivenciado com o propósito de inclusão. Neste contexto, os profissionais são responsáveis por garantir espaços capazes de socializar conhecimentos, assegurar respeito mútuo, além de dirimir culpas e sofrimentos.

(...) o diálogo... a gente conversa muito com eles... fala que tudo tem um tempo. O tempo deles... eles é que vão saber qual o tempo deles (Assistente social - afeto).

Para se relacionar com as questões específicas desses usuários que vivem com HIV, que apresentam demandas complexas, fragilidades pessoais, estigmas, processos de morbidade e finitude, os profissionais/facilitadores têm de abrir mão de suas 'verdades' particulares e posicionamentos radicais, para viabilizar uma determinada compreensão do tempo individual dos usuários. Entender o modo próprio que eles têm de ‘levar a vida'. 
Porque que é tão mais difícil aceitar, mesmo que uma mulher HIV positivo possa ter seu próprio direito à reprodução (Assistente social - solidariedade).

Como ali, que têm vários saberes que estão colocados, que tem uma cultura, que tem um conhecimento... (...) alguns medos... aí a gente vai trabalhando isso (Assistente social - pertencimento).

Assim, é necessário que os agentes desse processo (usuários e profissionais de saúde) relativizem suas falas e percepções de mundo, a fim de respeitar o posicionamento do outro no grupo.

Partindo do princípio que nas atividades educativas a participação do usuário é livre, torna-se possível assegurar envolvimento espontâneo com a dinâmica dos encontros, assim como sentimento de pertencimento e formação de vínculo. Esse engajamento facilita o processo de aprendizagem e proporciona oportunidades para abordar assuntos de interesse de todos.

A gente parte muito da demanda deles. Quer dizer, o assunto que eles abordam no grupo. Às vezes eles chegam, a gente tem uma proposta de discutir um assunto, mas aí eles colocam outro, dali a gente já parte, ou então daquele assunto a gente vai desenvolvendo outro." (Assistente social - afeto).

(...) acho que também não adianta a gente chegar ali e impor determinadas coisas... é estar organizando junto com eles (Cirurgiã-dentista - atenção).

Visto que a participação progressiva nos encontros pode contribuir para que cada um trabalhe seus sentimentos, emoções e expectativas, com o decorrer do tempo torna-se possível viabilizar ações que transgridam o evento doença. Ações que possibilitem a promoção de saúde numa concepção abrangente e que incentivem perspectivas de autocuidado, autopercepção, autorrespeito, autonomia e cidadania. Conforme Santos e colaboradores (2006), esse conjunto de pessoas deve interagir cooperativamente, privilegiando recursos sociais e individuais, a fim de realizar tarefas que minimizem perdas, desenvolvam autonomia e promovam a saúde.

Eu acho que rola uma coisa, uma coisa meio assim... exercício de cidadania. Eles se tornam cidadãos (Médico - liberdade).

A intenção dos profissionais em realizar educação em saúde nos espaços coletivos confirmou a necessidade de intermediar processos democráticos e participativos, além de contribuir para que os usuários assumissem posicionamentos corresponsáveis, sobretudo para a formação da cidadania com enfoque na promoção da saúde e na melhoria da qualidade de vida. 


\section{Considerações finais}

Ao longo do estudo, a educação em saúde foi abordada de diferentes maneiras, sendo vista pelos profissionais como modos de ensino e aprendizado recíprocos; repasse de informações, orientações e esclarecimentos; troca de ideias e experiências, bem como crescimento mútuo; processo reflexivo e participativo que contribui para minimizar sofrimentos, trabalhar expectativas e emoções, além de promover saúde, cidadania e qualidade de vida.

No âmbito da saúde, as ações educativas devem oportunizar o trabalho de valores ético-morais, desdobramentos socioafetivos e compromissos sociopolíticos, a fim de que os encontros e as relações, a partir da valorização de contextos socioeconômicos, políticos e culturais, estejam aptos a mediarem tanto mudanças pessoais quanto coletivas.

No entanto, em que medida esse estudo poderá contribuir com outras pesquisas e práticas profissionais desenvolvidas com pessoas que vivem com HIV?

A voz da educação em saúde, compartilhada entre profissionais de saúde e pessoas soropositivas para o HIV, contribui efetivamente para minimizar sofrimentos, aproximar e humanizar as relações interpessoais, auxiliar na produção de cuidados integrais, garantir o acesso aos serviços de saúde, operacionalizar medidas de prevenção e de reabilitação com fornecimento de insumos (preservativos e antirretrovirais) e suscitar movimentos cotidianos que atendam aos princípios de universalidade e integralidade, responsáveis por promover saúde e qualidade de vida.

\section{Nota do Editor}

Este artigo foi extraído da dissertação de mestrado intitulada $O$ 'mundo positivo' do HIV a partir da visão dos profissionais de saúde no município de Niterói - RJ, de Audrey Vidal Pereira, apresentada em 6 de abril de 2006 na Escola Nacional de Saúde Pública Sergio Arouca, Fundação Oswaldo Cruz (Ensp/Fiocruz). O primeiro autor realizou pesquisa de campo e participou de todas as etapas de produção do artigo. A segunda autora participou na condição de orientadora. O terceiro autor colaborou como co-orientador. 


\section{Notas}

1 Professor assistente da Escola de Enfermagem Aurora de Afonso Costa da Universidade Federal Fluminense (EEAAC/UFF), Brasil. Mestre em Ciências da Saúde pela Escola Nacional de Saúde Pública Sergio Arouca, da Fundação Oswaldo Cruz (Ensp/Fiocruz). <auviprof@yahoo.com.br>.

Correspondência: Universidade Federal Fluminense (UFF), Rua Dr. Celestino, 74, CEP 24.020-091, Centro, Niterói, Rio de Janeiro, Brasil.

2 Pesquisadora titular no Departamento de Administração e Planejamento em Saúde da Escola Nacional de Saúde Pública Sergio Arouca, Fundação Oswaldo Cruz (Ensp/Fiocruz). Doutora em Enfermagem pela Escola de Enfermagem Anna Nery, da Universidade Federal do Rio de Janeiro (UFRJ) <stiebler@ensp.fiocruz.br>

3 Pesquisador titular no Departamento de Administração e Planejamento em Saúde da Escola Nacional de Saúde Pública Sergio Arouca, Fundação Oswaldo Cruz (Ensp/Fiocruz). Doutor em Educação pela Faculdade de Educação da Universidade Federal do Rio de Janeiro (UFRJ).<aafilho@uol.com.br>

4 Se houver interesse em um aprofundamento teórico, são recomendadas algumas leituras que abordam as temáticas relativas à prática de grupo: Martins (2003), Paiva (2002), Santos et al. (2006), Sartori e Van der Sand (2004), Silveira e Ribeiro (2005), Silva et al. (2005), Torres, Hortale e Schall (2003), Pichon-Rivière. (1998), Rasera e Japur (2003) e Mota (2002).

\section{Referências}

AYRES, José Ricardo C. M. Práticas educativas e prevenção de HIV/Aids: lições aprendidas e desafios atuais. Interface: Comunicação, Saúde, Educação, Botucatu, v. 6, n. 11, p. 11-24, 2002.

BARDIN, Laurence. Análise de conteúdo. Ed. revista e atualizada. Lisboa: Edições 70, 2009.

BRASIL. Ministério da Saúde. Núcleo Técnico da Política Nacional de Humanização. HumanizaSUS: Política Nacional de Humanização - a humanização como eixo norteador das práticas de atenção e gestão em todas as instâncias do SUS. Brasília, DF:
Ministério da Saúde, 2004. Série B. Textos básicos de saúde.

CURY, Augusto J. Pais brilhantes, professores fascinantes. Rio de Janeiro: Sextante, 2003.

CZERESNIA, Dina; FREITAS, Carlos Machado. Promoção da saúde: conceitos, reflexões, tendências. Rio de Janeiro: Ed. Fiocruz, 2003.

DIAS, Valesca P.; SILVEIRA, Denise T.; WITT, Regina R. Educação em saúde: o trabalho de grupos em atenção primária. Revista de APS, Juiz de Fora, v. 12, n. 2, p. 221-227, abr./jun. 2009. 
FREIRE, Paulo. Pedagogia do oprimido. 24. ed. Rio de Janeiro: Paz e Terra, 1997.

Pedagogia da autonomia: saberes necessários à prática educativa. 25. ed. São Paulo: Paz e Terra, 1996.

GOLEMAN, Daniel. Inteligência emocional: a teoria revolucionária que define o que é ser inteligente. Rio de Janeiro: Objetiva, 2001.

MARCONDES, Willer B. Participação popular na saúde pelos caminhos da prática educativa. 2007. Tese (Doutorado em Saúde Pública) - Escola Nacional de Saúde Pública Sérgio Arouca, Fundação Oswaldo Cruz, Rio de Janeiro, 2007.

MARTINS, Sueli T. F. Processo grupal e a questão do poder em Martín-Baró. Psicologia \& Sociedade, Florianópolis, v. 15, n. 1, p. 201-217, jan./jun. 2003.

MERCHÁN-HAMANN, Edgar. Os ensinos da educação para saúde na prevenção de HIV/Aids: subsídios teóricos para a construção de uma práxis integral. Cadernos de Saúde Pública, Rio de Janeiro, 15, supl. 2, p. 85-92, 1999.

MOROSINI, Márcia V. G. C.; FONSECA, Angélica F.; PEREIRA, Isabel B. Educação e saúde na prática do agente comunitário. In: MARTINS, Carla Macedo; STAUFFER, Anakeila de Barros (Orgs.). Educação e saúde. Rio de Janeiro: Escola Politécnica Joaquim Venâncio/Fiocruz, 2007.

MOTA, Leonardo A. A solidariedade entre os alcoólicos anônimos: a dádiva da modernidade. 2002. Dissertação (Mestrado em Sociologia) - Universidade Federal do Ceará, 2002.

PAIVA, Vera. Sem mágicas soluções: a prevenção e o cuidado em HIV/AIDS e o processo de emancipação psicossocial. Interface: Comunicação, Saúde, Educação, Botucatu, v. 6 , n. 11, p. 25-38, ago. 2002.

PICHON-RIVIÈRE, Enrique. O processo grupal. 6. ed. São Paulo: Martins Fontes, 1998.
RASERA, Emerson F.; JAPUR, Marisa. Grupo de apoio aberto para pessoas portadoras do HIV: a construção da homogeneidade. Estudos de Psicologia, Natal, v. 8, n. 1, p. 55-62, 2003.

SANTOS, Luciane M. et al. Grupos de promoção à saúde no desenvolvimento da autonomia, condições de vida e saúde. Revista de Saúde Pública, São Paulo, n. 40, v. 2, p. 346-352, 2006.

SARTORI, Graziele S.; VAN DER SAND, Isabel Cristina P. Grupo de gestantes: espaço de conhecimentos, de trocas e de vínculos entre os participantes. Revista Eletrônica de Enfermagem, Goiânia, v. 6, n. 2, p. 153-165, 2004.

SILVA, Denise M. G. V. et al. Qualidade de vida na perspectiva de pessoas com problemas respiratórios crônicos: a contribuição de um grupo de convivência. Revista Latino-Americana de Enfermagem, Ribeirão Preto, v. 13, n. 1. p. 7-14, jan./fev. 2005.

SILVEIRA, Lia Márcia C.; RIBEIRO, Victoria Maria B. Grupo de adesão ao tratamento: espaço de 'ensinagem' para profissionais de saúde e pacientes, Interface: Comunicação, Saúde, Educação, Botucatu, v. 9, n. 6, p. 91104, set. 2004/fev. 2005.

STOTZ, Eduardo. Enfoques sobre educação popular e saúde. In: BRASIL. Ministério da Saúde. Secretaria de Gestão Estratégica e Participativa. Departamento de Apoio à Gestão Participativa. Caderno de Educação Popular e Saúde. Brasília, DF: Ministério da Saúde: 2007. p. 46-47. Série B. Textos básicos de saúde.

TORRES, Heloísa C.; HORTALE, Virginia A.; SCHALL, Virginia. A experiência de jogos em grupos operativos na educação em saúde para diabéticos. Cadernos de Saúde Pública, Rio de Janeiro, v. 19, n. 4, p. 1.039-1.047, jul./ago. 2003.

VASCONCELOS, Eymard M. Educação popular: instrumento de gestão participativa dos serviços de saúde. In: BRASIL. Ministério da Saúde. Secretaria de Gestão Estratégica e 
Participativa. Departamento de Apoio à Gestão Participativa. Caderno de Educação Popular e Saúde. Brasília, DF: Ministério da Saúde: 2007. p. 18-29. Série B. Textos básicos de saúde.
Educação popular: prática alternativa de uma estratégia de gestão participativa das políticas de saúde. Physis [on line], Rio de Janeiro, v. 14, n. 1, p. 67-83, 2004.

Recebido em 08/02/2010

Aprovado em 29/10/2010 